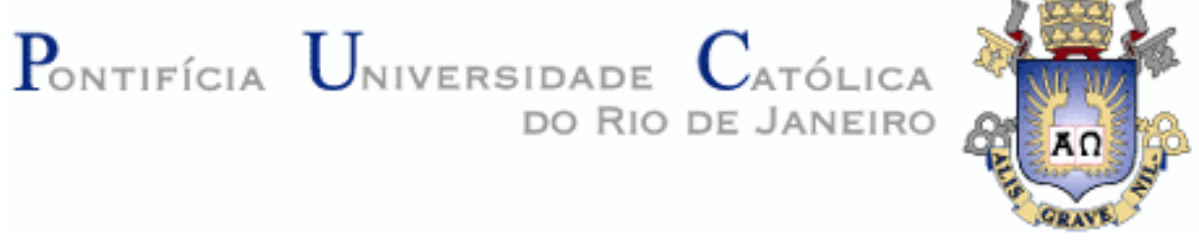

Denis de Miranda

\title{
A construção da identidade do oficial do Exército Brasileiro
}

Dissertação de Mestrado.

Dissertação apresentada ao Programa de Pósgraduação em Ciências sociais da PUC-Rio como requisito parcial para obtenção do título de Mestre em Ciências Sociais.

Orientador: Prof. Eduardo de Vasconcelos Raposo

Rio de Janeiro

Dezembro de 2012 


\section{A construção da identidade do oficial do Exército Brasileiro}

Dissertação apresentada como requisito parcial para obtenção do título de Mestre pelo Programa de Pós-Graduação em Ciências Sociais da PUCRio. Aprovada pela Comissão Examinadora abaixo assinada.

Prof. Eduardo de Vasconcelos Raposo

Orientador

Departamento de Ciências Sociais - PUC-Rio

Prof. Bernardo Sorj ludcovsky

UFRJ

Profa. Maria Alice Rezende de Carvalho Departamento de Ciências Sociais - PUC-Rio

Profa. Mônica Herz

Coordenadora Setorial do Centro de Ciências Sociais - PUC-Rio

Rio de Janeiro, 28 de dezembro de 2012 
Todos os direitos reservados. É proibida a reprodução total ou parcial do trabalho sem autorização da universidade, da autora e do orientador.

\section{Denis de Miranda}

É especialista em Comunicação Social, possui graduação em Ciências Militares pela Academia Militar das Agulhas Negras (1992), mestrado em Operações Militares pela Escola de Aperfeiçoamento de Oficiais (2000), especialização em Psicopedagogia pela UFRJ (2002) e MBA em Marketing pela Fundação Getúlio Vargas (2007). É pesquisador do Núcleo de Estudos Sociais das Instituições Militares Brasileiras e do PróDefesa.

Ficha Catalográfica

Miranda, Denis de

A construção da identidade do oficial do Exército Brasileiro / Denis de Miranda ; orientador: Eduardo de Vasconcelos Raposo. - 2012. 173 f. : il. (color.) ; $30 \mathrm{~cm}$

Dissertação (mestrado)-Pontifícia Universidade Católica do Rio de Janeiro, Departamento de Ciências Sociais, 2012.

Inclui bibliografia

1. Ciências Sociais - Teses. 2. Identidade. 3. Valores. 4. Exército. I. Raposo, Eduardo de Vasconcelos II. Pontifícia Universidade Católica do Rio de Janeiro. Departamento de Ciências Sociais. III. Título.

CDD: 300 


\section{Agradecimentos}

Ao meu professor orientador Eduardo Raposo pelas valiosas indicações, orientações e por sua permanente disponibilidade em me atender a qualquer hora.

Aos professores que participaram da Banca Examinadora Maria Alice Rezende de Carvalho e Bernardo Sorj que acreditaram neste projeto desde o início e pela honrosa disponibilização em avaliar o presente estudo.

Aos amigos do CEP: Sarita, Julio César, Camila, Daniel, Sandra da Hora, Débora, Adrianne e Ana Paula pela fé e incentivo, corrigindo meus textos desde o início, pelos livros e artigos indicados e cedidos. Sem eles não teria rompido a inércia e superado tantas barreiras para ser pesquisador.

À Vanusa Queiroz e Ana Roxo sempre presentes e dispostas, com carinho e atenção, no suporte de toda e qualquer demanda.

Às amigas pesquisadoras Daniela Wortmeyer e Lauriani Albertini que cederam seus textos acerca dos militares facilitando e orientando minhas análises e pesquisa.

Aos meus amigos e parceiros de trabalho Penoni e Ventura que compensaram minhas ausências, trabalhando dobrado, para que eu pudesse frequentar as aulas do mestrado.

Ao meu amigo e irmão Everton Araújo dos Santos que trilhou comigo as jornadas do mestrado desde a preparação inicial até a entrega do texto final, incentivandome e lutando ao meu lado contra os obstáculos que não foram poucos.

Aos meus chefes e companheiros do Exército Brasileiro que me apoiaram, incentivaram e contribuíram em todas as etapas deste trabalho.

Aos meus pais Josias, Catarina e Suzana que, além de dar amor, cuidaram para que nada faltasse, orações, ligações, mensagens e incentivos mil.

Aos meu filho único Guilherme que me ama incondicionalmente até mesmo nas ausências que foram necessárias ao longo desses três anos de estudo.

À minha amada mulher e melhor amiga Renata pelo incansável apoio e incentivo em todas as horas.

Ao meu Deus que é fiel e me surpreende com bênçãos inimagináveis! 


\section{Resumo}

Miranda, Denis de. Raposo, Eduardo de Vasconcelos. A construção da identidade do oficial do Exército Brasileiro. Rio de Janeiro, 2013. 173 p. Dissertação de mestrado. Departamento de Ciências Sociais, Pontifícia Universidade Católica do Rio de Janeiro.

A presente dissertação é uma análise da construção da identidade do oficial do Exército Brasileiro. Ampla e inédita pesquisa de opinião realizada com mais de seiscentos oficiais de carreira formados na Academia Militar das Agulhas Negras (AMAN) clarifica o perfil atual da identidade dos oficiais do Exército destacando as variações impulsionadas pela pós-modernidade. A pergunta que norteia todo o trabalho é: com a chegada dessas transformações sociais a partir da década de 1970, a identidade dos oficiais do Exército Brasileiro sofreu alterações? Inicialmente é realizada uma exposição teórica acerca do conceito de identidade com abordagens da sociologia e textos da psicologia e filosofia, em que são traçados paralelos entre identidade e caráter, identidade e reconhecimento, diferença e identidade, além das abordagens da identidade profissional, institucionalização e valores do trabalho e das organizações. As identidades na modernidade e pós-modernidade são descritas sob uma visão sociológica abordando-se as diferenças impostas aos indivíduos e instituições nas relações pessoais e profissionais, caracterizando a necessária flexibilização das identidades, inclusive no meio militar. Também são utilizadas visões de autores consagrados acerca da identidade do homem brasileiro e dos militares, destacando os valores que cultuam, tendo por base biografias dos patronos do exército. Finalizando a análise, mediante tratamento estatístico quantitativo e qualitativo, toda a teorização é confrontada com os dados obtidos na pesquisa de opinião realizada com os oficiais de carreira para a obtenção do perfil da identidade dos oficiais do Exército destacando as variações impulsionadas pela pós-modernidade.

\section{Palavras-chave}

Identidade; valores; Exército. 


\section{Abstract}

Miranda, Denis de. Raposo, Eduardo de Vasconcelos. (Advisor) The construction of the identity of the official Brazilian Army. Rio de Janeiro, 2013. 173 p. MSc. Dissertation. Departamento de Ciências Sociais, Pontifícia Universidade Católica do Rio de Janeiro.

This thesis is an analysis of the construction of the the official Brazilian Army identity. Extensive and unprecedented survey conducted with over six hundred trained career officers at the Military Academy of Agulhas Negras (AMAN) clarifies the current profile of the identity of army officers focusing on variations driven by postmodernity. The question that guides all the work is: with the arrival of these social transformations from the 1970s, has the identity of the Brazilian Army changed? First there is an exhibition about the theoretical concept of identity with approaches from sociology and psychology, and philosophy texts, in which parallels are drawn between identity and character, identity and recognition, identity and difference, besides the approaches of professional identity, values and institutionalization and labor organizations. The identities in modernity and post-modernity are described from a sociological view addressing the differences imposed on individuals and institutions in personal and professional relationships, characterizing the necessary flexibility of identities, including the military life. Beyond that, visions of acclaimed authors about the identity of the man and the Brazilian military, highlighting the values worshiped based on biographies of patrons Army. Concluding the analysis by statistical quantitative and qualitative, all the theorizing is confronted with the data obtained in the survey conducted with career officers for obtaining the profile of the identity of army officers focusing on variations driven by postmodernity.

\section{Keywords}

Identify; values; army 


\section{Sumário}

$\begin{array}{ll}\text { Introdução } & 11\end{array}$

1. Definições de identidade 14

1.1. Identidade 14

1.2. Diferença e identidade 16

$\begin{array}{ll}\text { 1.2.1. Multiculturalismos } & 16\end{array}$

1.2.2. A concepção pós-estruturalista de identidade 18

$\begin{array}{ll}\text { 1.3. Identidade profissional } & 18\end{array}$

1.4. Comportamento, atitude e valor 20

1.5. Valores do trabalho e das organizações $\quad 25$

$\begin{array}{ll}\text { 1.6. Identidade e caráter } & 27\end{array}$

1.7. Identidade e reconhecimento $\quad 29$

1.8. Institucionalização e identidade $\quad 30$

1.9. A identidade profissional dos militares 32

Conclusão $\quad 35$

2. Identidade moderna e pós-moderna 36

2.1. Harvey e a condição pós-moderna 36

2.2. A identidade descrita por Bauman $\quad 40$

2.3. A identidade cultural na pós-modernidade descrita por Stuart Hall $\quad 43$

2.4. A modernização reflexiva de Beck e Giddens 49

Conclusão $\quad 50$

3. Sociedade, instituições e militares $\quad 55$

3.1. A construção social e institucional da realidade 56

3.2. A sociedade brasileira 58

3.3. Teorias do Brasil 66

3.4. A formação da instituição Exército Brasileiro 76

Conclusão $\quad 84$

4. Os valores militares 86

4.1. A identidade dos patronos $\quad 89$

4.1.1. Caxias - Patrono do Exército 91

4.1.2. Sampaio - Patrono da Infantaria 96

4.1.3. Osório - Patrono da Cavalaria 99

4.2. Patronos para o exército - uma nova tradição 102

$\begin{array}{ll}\text { Conclusão } & 103\end{array}$

5. Análise do Survey 104

5.1. A necessidade de aplicação da pesquisa 104

5.2. O método da pesquisa 105

5.3. Escolha da plataforma de aplicação do questionário 105

5.4. Universo e amostra 107

5.5. Respostas obtidas do questionário aplicado 109

6. Conclusão 157 
Referências bibliográficas 


\section{Lista de figuras}

Figura 1 - Elementos das Bandeiras

Figura 2 - Cartaz da Brigada de Operações Especiais do Exército 
Lista de gráficos

Gráfico síntese do survey 